\title{
CAPÍTULO 15: ALTERNATIVAS SUSTENTÁVEIS PARA O MANEJO DE FUNGOS E INSETOS DE ARMAZENAMENTO EM GRÃOS DE MILHO PARA A AGRICULTURA FAMILIAR
}

\author{
CHAPTER 15: SUSTAINABLE ALTERNATIVES FOR THE MANAGEMENT OF \\ STORAGE INSECTS AND FUNGI IN MAIZE GRAINS FOR FAMILY \\ AGRICULTURE
}

\author{
Gisele Silva Oliveira ${ }^{1}$; Oziana Ferreira da Silva Oliveira ${ }^{2}$
}

\section{Resumo}

O milho é um grão de grande valor econômico e social para a agricultura familiar por sua diversidade de usos, podendo ser empregado na alimentação humana e animal. $O$ armazenamento é uma estratégia adotada pelos produtores para garantir sua disponibilidade ao longo das épocas de escassez. Promover a sanidade desse material muitas vezes é um fator limitante devido as condições precárias de armazenamento, o surgimento de fungos e insetos que danificam a massa de grãos diminui a qualidade do produto. A partir disso, buscou-se através de uma revisão de literatura estratégias que visem o controle de fungos e insetos de armazenamento baseados em produtos de origem vegetal e de fácil disponibilidade para o agricultor. Há um grande potencial no uso de extratos, óleos e pós de origem vegetal para o combate de fungos e insetos de armazenamento, visto que muitos dos materiais podem ser encontrados na propriedade rural ou serem adquiridos por um baixo custo, sendo viável para o uso em condições de armazenamento e atuando de diversas formas sobre os problemas fitossanitários. Ainda são necessárias ações de assistência técnica e extensão rural para divulgar essas práticas, além de pesquisas a respeito do potencial de espécies vegetais locais.

Palavras-Chave: Micotoxinas, Perda econômica, Produtos botânicos.

\begin{abstract}
Corn is a grain of great economic and social value for family agriculture due to its diversity of uses and can be used in human and animal food. Storage is a strategy adopted by producers to ensure its availability during times of scarcity. Promoting the health of this material is often a limiting factor due to the precarious storage conditions, the appearance of fungi and insects that damage the grain mass decreases the quality of the product. From this, strategies were sought through a literature review aimed at controlling fungi and storage insects based on products of plant origin and easily available to the farmer. There is great potential in the use of extracts, oils and powders of plant origin to combat fungi and storage insects, since many of the materials can be found on the rural property or can be purchased at low cost, being viable for use in storage conditions and acting in various ways on phytosanitary problems. Technical assistance and rural extension actions are still needed to publicize these practices, in addition to research on the potential of local plant species.
\end{abstract}

Keywords: Mycotoxins, Economic loss, Botanical products

\footnotetext{
${ }^{1}$ Bacharelado em agronomia, Instituto Federal de Pernambuco, Liveirag@gmail.com

${ }^{2}$ Licenciada em Ciências Biológicas, Universidade Federal de Pernambuco, Ozianaferreira1 @ hotmail.com
} 


\section{Introdução}

O milho (Zea mays L.) é um dos grãos mais importantes produzidos no Brasil, alcançando cerca de 100,04 milhões de toneladas de grãos produzidos no país, sendo o estado do Mato Grosso o maior produtor nacional (CONAB, 2020).

Além de ser uma importante commodity brasileira, o milho ganha destaque na agricultura familiar e em populações de baixa renda, representando um importante recurso econômico e nutricional, uma vez que ele pode ser comercializado, garantindo renda ao produtor, ou até mesmo utilizado como fonte energética na alimentação humana e animal (CRUZ et al., 2011; PIMENTEL et al., 2011).

Os grãos são colhidos quando atingem a maturidade fisiológica e devem ser secos e conservados de maneira adequada a fim de evitar perdas na qualidade do produto, o armazenamento de grãos e sementes é uma estratégia antiga do produtor para garantir recursos alimentares ou econômicos e fonte de propagação de espécies em épocas de escassez ou fora da época de cultivo, entretanto o baixo uso e até mesmo a falta de acesso a tecnologias por parte desses agricultores levam a perda do material armazenado pelo ataque de roedores, insetospraga e fungos de armazenamento que reduzem a higiene dos grãos e podem produzir micotoxinas prejudiciais à saúde humana e animal (SANTOS, 2006; CRUZ et al., 2011; HAGSTRUM; PHILLIPS, 2017; SENAR, 2018).

Os grãos armazenados estão sujeitos a fatores que podem causar sua rápida degradação, fatores externos, como a temperatura e a umidade, influenciam diretamente na qualidade do produto a longo prazo, os ambientes onde não é possível realizar o controle dessas condições tornam-se propícios ao ataque de pragas (BERGAMASCHI; MATZENAUER, 2014; SENAR, 2018). Teores de umidade acima de $13 \%$ tornam os grãos mais susceptíveis ao desenvolvimento de fungos fitopatogênicos que, ao longo de sua colonização, provocam o aquecimento da massa de grãos, alterando seu aroma e sabor, enquanto que temperaturas entre 25 e $34{ }^{\circ} \mathrm{C}$ podem favorecer o estabelecimento de insetos-praga (CASELA; FERREIRA; PINTO, 2006; SENAR, 2018; ANDRADE et al., 2020).

As infestações de fungos muitas vezes iniciam em campo, fungos do gênero Fusarium spp. possuem a característica de alterar o sabor provocando o "grão ardido", tornando-se um problema para o consumo pela presença de micotoxinas como fumonisinas, zearalenona, vomitoxinas, entre outras, que podem causar danos à saúde (CASELA; FERREIRA; PINTO, 2006; JIMENEZ-GARCIA et al., 2018). O gênero Aspergillus representa um dos diversos gêneros de fungos patogênicos que causam perdas na pré e pós-colheita de grãos de milho, com aproximadamente 200 espécies que produzem metabólitos secundários que, além de causar a 
degradação do material armazenado e perda econômica, podem provocar intoxicações ou ser letal para humanos e animais, não só através do consumo, mas também a exposição aos esporos pode causar danos ao agricultor que está diariamente nas instalações de armazenamento de grãos, podendo causar doenças pulmonares, insuficiência hepática e levar à morte (ELIAS et al., 2015; SCAZZOCCHIO, 2019). O gênero Colletotrichum é um dos mais comuns associados a problemas de pós-colheita, causando a doença conhecida por antracnose, que se caracteriza como o apodrecimento do tecido vegetal e pode causar perdas de até $100 \%$ da produção em condições de armazenamento (DEAN et al., 2012)

Um outro fator a ser mencionado é a presença de insetos-praga, o Sitophilus zeamais Motsch., Sitotroga cerearella Olivier e Prostephanus truncatus Horn são os insetos de maior relevância para o milho em condições de armazenamento, causando percas pelo consumo do grão, reduzindo o seu peso, provocando a diminuição do valor econômico do produto pela presença de ovos e excrementos dos insetos e redução do valor nutricional, além de diminuir a capacidade de germinação das sementes e causar o aquecimento dos grãos, os insetos podem ainda ser disseminadores de esporos de fungos e o dano causado no grão pode servir de entrada para microrganismos fitopatogênicos por aumentarem a susceptibilidade do milho a agentes externos (SANTOS, 2006; ELIAS et al., 2015; LORINI, 2015).

Medidas para atenuar os prejuízos causados por essas pragas devem ser tomadas desde o campo, o controle com químicos sintéticos é o mais difundido, mas apresenta pontos negativos como o seu alto custo e a presença de resíduos nos alimentos e no ambiente, sendo um risco tanto para a saúde humana quanto para o agroecossistema, porém é fundamental práticas como a colheita no estádio de desenvolvimento correto, a limpeza, secagem e seleção dos grãos sadios a fim de evitar infestações oriundas do campo, além disso, outras estratégias podem ser tomadas, os recipientes e/ou embalagens utilizadas para armazenar devem ser uma aliada na hora de guardar tais produtos, sacos hermeticamente fechados com umidade de $18 \%$ são capazes de reduzir a população de S. zeamais durante 180 dias pelo aumento da concentração de dióxido de carbono na embalagem, levando os gorgulhos à morte, mas em contrapartida favorecem o aparecimento de fungos que produzem micotoxinas, o uso de variedades resistentes ao ataque de pragas e doenças que possuem características físicas como a dureza e densidade ou químicas como conteúdo de proteína bruta e teor de amilose podem tornar os grãos mais resistentes ao ataque e estabelecimento de fungos e diminuir o consumo dos insetos e consequentemente diminuir a velocidade de infestação, o controle biológico com espécies como Heterorhabditis bacteriophora, Steinernema carpocapsae e S. feltiae mostra-se promissor ao reduzir algumas populações de insetos-praga, mas ainda está longe da realidade 
do agricultor (LIKHAYO et al., 2018; MBATA; IVEY; SHAPIRO-ILAN, 2018; SENAR, 2018; NGOM et al., 2020).

Para o controle de pragas de produtos armazenados, as técnicas foram aprimoradas ao longo dos anos e também passada por diversas gerações os conhecimentos obtidos, a troca e o comércio de mercadorias favoreceu a disseminação de doenças e pragas agrícolas, com isso, o uso de cinzas e carvão vegetal, pó de giz e utilização de plantas tóxicas foram algumas das técnicas utilizadas na antiguidade para reduzir a perda de produtos armazenados (HAGSTRUM; PHILLIPS, 2017).

Dessa forma, o manejo de pragas de grãos armazenados pode ser realizado de diversas outras maneiras, a utilização de produtos alternativos à base de vegetais para a conservação de sementes e grãos pode reunir diversos mecanismos de ação e reduzir os níveis de infestação de insetos e fungos, agregando mais uma forma de combate contra os problemas nos grãos (HIKAL; BAESHEN; SAID-AL AHL, 2017; RIBEIRO; VENDRAMIM, 2019). Produtos botânicos são uma alternativa aos químicos sintéticos pela acessibilidade e baixo custo de produção, sendo uma tecnologia viável para agricultores com poucos recursos financeiros (MIDEGA et al., 2016; OKEREKE; GODWIN-EGEIN; MORDI, 2017; MACHINGURA, 2019).

A partir disso, buscou-se investigar através de uma revisão da literatura estratégias de controle sustentável e de baixo custo que apresentam evidencias científicas a respeito de sua eficiência contra os principais fungos e insetos-praga relacionados ao armazenamento do milho.

A pesquisa trata-se de uma revisão da literatura de caráter qualitativa. Foram selecionados trabalhos científicos entre os anos de 2016 a 2020 nas plataformas Science Direct, Portal de periódicos CAPES e Google Acadêmico nos idiomas português e inglês com a ajuda dos descritores: Zea mays, armazenamento e produtos botânicos. Os trabalhos científicos encontrados foram submetidos a avaliação de título e resumo, e os que se enquadraram no tema principal foram selecionados. Após essa triagem, os estudos foram analisados buscando extrair as informações desejadas para a construção deste trabalho.

\section{Desenvolvimento}

O controle dos problemas fitossanitários em armazenamentos de grãos de milho pode ser realizado com a utilização de extratos, óleos e pós derivados de espécies vegetais, sejam folhas, raízes, frutos, ramos ou sementes que muitas vezes são encontradas na propriedade rural do agricultor ou são materiais possíveis de serem adquiridos por um baixo custo, esses produtos atuam como deterrente alimentar ou de oviposição, repelente, como regulador de crescimento 
ou inibindo a progênie dos insetos, nos fungos, cessa o crescimento, impede o estabelecimento da colônia ou retarda seu crescimento, entre outros fatores que garantem sucesso na sua utilização (TOFEL et al., 2016; HAGSTRUM; PHILLIPS, 2017; AGALE et al., 2020).

\subsection{Extratos}

O extrato de folhas de Corchorus olitorius L. impediu completamente o crescimento das colônias fúngicas de Fusarium sp. e Aspergillus sp. (AKWAJI; UMANA; OKON, 2016). Em ensaios in vitro os extratos aquosos de Gongronema latifolium Benth. e Vernonia amygdalina Delile reduziram consideravelmente o crescimento de A. niger, extrato das sementes de Moringa oleífera Lam. apresentou eficácia de 95,5\% no controle de fungos de armazenamento e não comprometeu a qualidade de germinação das sementes, já o extrato de Piper nigrum L. inibiu o desenvolvimento de fungos em sementes de milho estocadas e não prejudicou a germinação (FONTE, 2016; OKEREKE; GODWIN-EGEIN; MORDI, 2017; SILVA, 2018).

O extrato etanólico de folhas de Chromolaena odorata L. em S. zeamais reduziu a progênie, porém não apresentou efeito repelente sobre os adultos (JNR; ABUGRI; AFUN, 2016). Extratos de espécies da família Annonaceae mostram-se promissores no controle do $S$. zeamais por causar mortalidade e reduzir drasticamente a progênie (RIBEIRO, 2016). Extratos aquosos de folhas de Pterocarpus santalinoides causou mortalidade e diminuição da emergência de adultos de $S$. zeamais, aumentando a mortalidade a medida que os insetos foram expostos a doses e períodos de tempo maiores, em consequência, os danos por perfuração e a perca de peso diminuíram (NKECHI et al., 2018). O extrato de folhas de Eucalyptus sp. foi capaz de controlar a população de $S$. zeamais por 3 meses em condições de armazenamento (TANKA, 2018). O extrato de Hyptis suaveolens L. causou repelência de insetos de S. zeamais, além disso, foi capaz de diminuir a emergência e causar mortalidade (GARIBA, 2018).

O extrato preparado com a casca de Citrus sinensis L. foi capaz de controlar as infestações de $S$. cerealella sem afetar a qualidade de germinação das sementes do milho, garantindo a qualidade fisiológica e diminuindo a perca de peso das sementes (CARVALHO et al., 2017).

Em P. truncatus os extratos de Lantana camara L., M. oleifera, C. sinensis e Hyptis suaveolens L. reduziu a sobrevivência dos insetos quando os extratos foram aplicados na fase de ovo e também houve redução na emergência de adultos, porém $H$. suaveolens obteve maior atividade repelente sobre os insetos, esses extratos formam capazes de diminuir os danos durante o período de armazenamento (GARIBA, 2018). 


\section{2 Óleos}

O óleo essencial de Curcuma longa L. apresentou efeito antifúngico e antiaflatoxigênica em A. flavus (HU et al., 2017). Os óleos essenciais de Cinnamomum sp. e Cymbopogon sp. foram eficazes no controle de Aspergillus sp. (MORAES, 2018). O óleo de Zingiber officinale Rosc. foi capaz de inibir o crescimento e a produção de aflotoxinas de $A$. flavus, sendo uma alternativa aos controles sintéticos (NERILO et al., 2020).

Óleo essencial do rizoma de Cochlospermum panchonii Hook ao ser avaliado em sementes de milho conseguiu reduzir o crescimento micelial de $C$. graminicola e não afetou o vigor germinativo das sementes (OUATTARA, et al., 2018). O óleo essencial de Cymbopogon winterianus Jowitt inibiu o crescimento de C. gloeosporioides e C. falcatum por diminuir a germinação dos esporos dos fungos (BALENDRES; CUEVA, 2019). O oléo essencial de Caryocar brasiliense Cambess mostrou-se eficaz no controle de Colletotrichum sp. (LIMA, 2019).

O óleo de Lippia graveolens Kunth. apresentou compostos que podem causar toxicidade fumigante contra $S$. zeamais e inibiu o crescimento de $F$. verticillioides demonstrando sua capacidade protetora (PESCHIUTTA et al., 2016). O óleo essencial de Eucalyptus camaldulensis Dehnh. inibiu completamente o crescimento de F. oxysporum, F. solani, F. verticillioides, $F$. proliferatum, e $F$. subglutinans, sendo sua eficácia uma importante ferramenta para a substituição de químicos sintético (GAKUUBI; MAINA; WAGACHA, 2017). O oléo essencial de Cananga odorata inibiu o crescimento fúngico de $F$. graminearum e reduziu a produção de micotoxinas por ele produzido (KALAGATUR et al., 2018). O óleo essencial de Cymbopogon martinii diminuiu o crescimento micelial de $F$. verticillioides reduzindo também o número de sementes de milho infectadas pelo fungo (ALVES et al., 2019). Os óleos essenciais de Cinnamomum zeylanicum, folhas de C. martinii, Citrus aurantium L. $e$ Mentha viridi L. demonstraram ser eficazes na redução da quantidade de zearalenona produzida por Fusarium spp., além de dificultar o crescimento do fungo (PERCZAK et al., 2020).

Os óleos essenciais de Syzygium aromaticum L. e Mentha pulegium L. possuem capacidade antifúngica em condições de armazenamento (BENTO, 2016) O óleo das folhas de Lippia multiflora Moldenk em A. flavus impediu o crescimento fúngico, porém também impediu a germinação das sementes de milho (MOHAMED et al., 2020).

O óleo de Ocimum kilimandscharicum Guerke foi capaz de reduzir os danos causados por S. zeamais (SM et al., 2018). O óleo extraído das sementes de Azadirachta indica A. Juss, apesar de não causar mortalidade direta dos adultos de $S$. zeamais, é capaz de causar efeitos subletais, ele inibe a alimentação deste inseto, o que pode ter levado a morte por desnutrição, 
atua como regulador de crescimento, podendo causar mortalidade em estágios imaturos e afeta a progênie e assim, diminui a infestação ao longo das gerações, chegando a eliminação da progênie em alguns casos, além disso, o óleo de $A$. indica consegue manter suas propriedades inseticidas por mais tempo quando comparado a óleos de Cymbopogon winterianus Jowitt, Cinnamomum verum L. e Eucalyptus globulus L. (TOFEL et al., 2016; TOFEl et al., 2017; MINKS, 2019). Em S. zeamais o óleo das folhas de Croton rudolphianus Müll. Arg. causou mortalidade dos insetos adultos por ingestão, quando utilizado no substrato alimentar, e também morte por contato ao ser aplicado diretamente nos insetos, além de apresentar efeito atrativo aos insetos (RIBEIRO et al., 2019). O óleo de L. camara causou repelência de S. zeamais (AYALEW, 2020).

Quando utilizado os óleos de Artemisia khorassanica Podl. e Artemisia sieberi Bess em S. cerealella, além de causar mortalidade, em baixas concentrações eles provocaram efeitos subletais, como o aumento do tempo de desenvolvimento dos ovos e diminuição da fase adulta e da fecundidade do inseto-praga (NASERI et al., 2017). O óleo essencial das raízes de Carlina acaulis L. causou mortalidade superior a $97 \%$ em indivíduos de P. truncatus quando expostos por 3 dias (KAVALLIERATOS et al., 2020).

\subsection{Pós}

O pó das folhas de Plectranthus glandulosus Hook foi capaz de causar mortalidade em S. zeamais e sua eficiência continuou alta mesmo quando as folhas foram submetidas a secagem ao sol, indicando que os componentes que causam a mortalidade dos insetos não são perdidos quando o material vegetal é exposto a radiação solar (TOFEl et al., 2017). A terra de diatomácea é uma outra alternativa no controle de $S$. zeamais, apesar de não ser de origem vegetal, é um pó inerte que tem efeito abrasivo que ao entrar em contato com a epicutícula do inseto rompe a camada de cera protetora e induz a perda de água do corpo do inseto, causando morte por dessecação e, por isso, pode ser utilizada em conjunto com produtos botânicos para garantir a eliminação dos problemas (RIBEIRO; LOVATTO; VENDRAMIM, 2018).

O Pó de Eucalyptus citriodora Hook foi capaz de repelir S. zeamais, diminuindo a oviposição na massa de grãos (MACHINGURA, 2019). Os pós de Nicotiana tabacum L., Coffea arábica L. e Baccharis trimera Less. foram capazes de reduzir a alimentação larval de $S$. zeamais, além de diminuir a quantidade e o peso de insetos adultos emergidos, causando um menor consumo de grãos (WENNECK et al., 2020). O pó de folhas de $L$. camara apresentou atividade repelente contra S. zeamais (AYALEW, 2020). 
Em S. cereallela o pó de folhas A. indica de foi capaz de controlar a praga em condições de armazenamento (VERMA et al., 2016). O pó de Aloe marlothii mostrou ser eficaz no controle de P. truncatus, garantindo a sanidade dos grãos estocados (MUCHIRIRI, 2018). Os pós foliares de Chromolaena odorata, Tithonia diversifolia Hemsl., Theobroma cacao L., A. indica, Citrus sinensis L. quando utilizados junto ao pó de própolis mostraram eficácia no controle de $P$. truncatus em milho armazenado (OSIPITAN et al., 2018). O Pó de E. citriodora foi capaz de repelir P. truncates (MACHINGURA, 2019).

\subsection{Discussão}

Os extratos, óleos e pós obtidos de espécies vegetais é uma ferramenta importante na manutenção da sanidade no ambiente de armazenamento, pois possuem diversos compostos que atuam de diferentes formas, tanto no controle do crescimento fúngico, na germinação de esporos e na produção de micotoxinas, como na mortalidade e fisiologia do inseto, variando de acordo com a espécie vegetal utilizada (HIKAL; BAESHEN; SAID-AL AHL, 2017; HU et al., 2017; AGALE et al., 2020).

A repelência é uma característica relevante, visto que evita que os insetos-praga se estabeleçam no milho, evitando assim a perda pelo ataque da praga, alguns fungos como o $F$. verticillioides, que causa a podridão do milho, é um fungo de armazenamento que quando há a interação fungo-grão emite compostos orgânicos voláteis que tornam o grão menos atrativo para o S. zeamais e, dessa forma, reduz o dano pelo inseto, causando um efeito protetor aos grãos de milho, porém aumenta o dano pelo fungo (USSEGLIO et al., 2017; MACHINGURA, 2019).

Produtos alternativos à base de vegetais que apresentam atividade atrativa e inseticida podem ser utilizados como iscas tóxicas, uma vez que quando misturados ao substrato alimentar tornam-se mais atrativos que o substrato sozinho, dessa forma, mesmo quando o controle não apresenta $100 \%$ de eficácia, ele ainda pode ser utilizado alinhado a outras práticas de manejo para garantir a sanidade do milho armazenado (BENTO, 2016; HIKAL; BAESHEN; SAIDAL AHL, 2017; RIBEIRO et al., 2019).

A utilização dos pós é uma ferramenta interessante, uma vez que cria uma barreira física entre o grão e o fungo e/ou inseto, dificultando o estabelecimento, além disso, em insetos podem causar asfixia por obstruir os espiráculos e traqueias, já os óleos essenciais apesar de serem ferramentas mais seguras em relação aos inseticidas químicos, apresentam limitações como o sabor residual que alguns óleos podem deixar nos grãos, utilizar doses menores pode melhorar 
o gosto, mas ao mesmo tempo diminui a capacidade fungicida e inseticida (TOFEL et al., 2016; HAGSTRUM; PHILLIPS, 2017; HIKAL; BAESHEN; SAID-AL AHL, 2017).

Outros fatores que podem ser limitantes à utilização de produtos vegetais é em relação a sua ação ao longo do tempo, algumas propriedades que garantem a capacidade fungicida e inseticida de extratos, óleos e pós podem se degradar facilmente com a temperatura, exposição à luz e umidade, causando um decréscimo na sua eficiência à medida que aumenta o tempo acondicionado, por outro lado, a alta volatilidade dos óleos pode ser um ponto positivo ao ser utilizada na fumigação de insetos, uma vez que apresentam baixo risco para o produtor ao manusear o produto, outro ponto importante é que muitos desses óleos utilizados apresentam diversos compostos com ação fungicida que inibem a produção de micotoxinas, podendo atuar tanto no inseto quanto no fungo (TOFEL et al., 2016; NASERI et al., 2017; KALAGATUR et al., 2018).

Os produtos de origem vegetal mostram-se promissores no controle de fungos e insetos de armazenamento, a utilização deles alinhada a boas práticas de colheita e pós-colheita pode garantir uma vida útil maior e com melhor qualidade para os grãos e sementes de milho (MIDEGA et al., 2016; AGALE et al., 2020).

Ainda assim é importante a realização de avaliações quanto a durabilidade em condições reais de armazenamento para garantir uma maior vida útil desses produtos, a fitotoxidez no milho é outro parâmetro a ser analisado, pois mesmo possuindo atividade fungicida ou inseticida, alguns produtos podem diminuir a qualidade da semente e do grão armazenado, ainda é necessário a investigação de seus efeitos em organismos não-pragas (SOUJANYA et al., 2016; TOFEL et al., 2016; MORAES, 2018).

\section{Considerações Finais}

A partir do levantamento bibliográfico efetuado, esta revisão fornece um panorama a respeito de algumas espécies vegetais e suas formas de uso que podem ser empregadas no controle de fungos e insetos-praga no armazenamento do milho realizado na agricultura familiar, podendo ser aplicadas na forma de extratos, óleos ou pós. Os óleos vegetais se destacam como estratégias promissoras no combate de diversas espécies de fungos e insetos.

A alta degradabilidade ao longo do tempo é um fator interessante a medida que não gera resíduos para o meio ambiente, mas pode ser um fator limitante devido ao seu curto prazo de proteção, dessa forma, esses produtos podem ser empregados alinhados a outras práticas de conservação dos grãos e sementes que iniciam desde a colheita, seleção do material a ser 
guardado e do recipiente a ser utilizado, assim o agricultor poderá contar com mais uma tática de proteção para a sua produção.

São necessárias mais pesquisas a respeito do potencial de espécies locais para a proteção de grãos, assim como da associação de diferentes produtos vegetais e também o seu efeito em inimigos-naturais.

Por fim, é fundamental ações de assistência técnica e extensão rural que visem difundir esses conhecimentos, visto que são estratégias sustentáveis e de baixo custo para os agricultores familiares.

\section{Referências}

AGALE, S. V. et al. Chapter-3 Botanicals Methods of Plant Disease Control. Current Research and Innovations in Plant Pathology, p. 29, 2020.

AKWAJI, P. I.; UMANA, E. J.; OKON, E. I. Phytochemical and Antifungal Activity of Leaf Extracts of Corchorus olitorius and Gongronema latifolium on Fungi Associated with PostHarvest Deterioration of Maize (Zea mays) Seeds in Oban Community, Nigeria. World Scientific News, v. 53, n. 3, p. 157-177, 2016.

ALVES, F. et al. Control of Fusarium verticillioides using Palmarosa essential oil (Cymbopogon martinii). Int. J. Curr. Microbiol. App. Sci, v. 8, n. 5, p. 484-494, 2019.

ANDRADE, J. G. et al. Diagnóstico das técnicas de produção e armazenamento de sementes crioulas em assentamentos rurais de Aparecida, Paraíba, Brasil. Research, Society and Development, v. 9, n. 5, p. e130953147, 2020.

AYALEW, A. A. Insecticidal activity of Lantana camara extract oil on controlling maize grain weevils. Toxicology Research and Application, v. 4, p. 1-10, 2020.

BALENDRES, M. A. O.; CUEVA, F. M. D. Growth-inhibiting activity of citronella essential oil to multiple fungal plant pathogens. bioRxiv, p. 860718, 2019.

BENTO, M. G. R. Avaliação da atividade fungicida de óleos essenciais e suas substâncias ativas no controlo de fungos de armazenamento. 2016. $121 \mathrm{f}$. Dissertação (Mestrado em Engenharia Agronómica, especialização em Proteção de Plantas) - Instituto Superior de Agronomia da Universidade de Lisboa, Lisboa, 2016.

BERGAMASCHI, H.; MATZENAUER, R. O milho e o clima. Porto Alegre: Emater/RSAscar, 2014. 84 p.

CARVALHO, R. L. L. et al. Controle alternativo de Sitotroga cerealella em sementes de milho armazenadas. Biodiversidade, v. 16, n. 1, 2017.

CASELA, C. R.; FERREIRA, A. S.; PINTO, N. F. J. A. Doenças na Cultura do Milho. Sete Lagoas - MG: Embrapa, 2006, 14 p. (Circular técnica, 83). 
CONAB, Companhia Nacional de Abastecimento. Acompanhamento de safra brasileiro grãos: Quinto levantamento, fevereiro 2020 - safra 2019/20. Brasília: Companhia Nacional de Abastecimento. 2020. Disponível em: https://www.conab.gov.br/index.php/infoagro/safras/graos. Acesso em: 03 jul. 2020.

CRUZ, J. C. et al. Produção de milho na agricultura familiar. Sete Lagoas - MG: Embrapa, 2011, 42 p. (Circular técnica, 159).

DEAN, R. et al. The Top 10 fungal pathogens in molecular plant pathology. Molecular plant pathology, v. 13, n. 4, p. 414-430, 2012.

ELIAS, M. C. et al. Tecnologias de pré-armazenamento, armazenamento e conservação de grãos. Material didático. Universidade Federal de Pelotas. Pelotas, RS, 2015.

FONTE, R. N. Uso de extratos vegetais e terra diatomácea associados ao condicionamento fisiológico no tratamento e armazenamento de sementes de milho (Zea mays L.). 2016. 102 f. Tese (Doutorado em Fitotecnia) - Universidade Federal Rural Do Rio De Janeiro, Seropédica, RJ, 2016.

GAKUUBI, M. M.; MAINA, A. W.; WAGACHA, J. M. Antifungal activity of essential oil of Eucalyptus camaldulensis dehnh. against selected Fusarium spp. International journal of microbiology, v. 2017, 2017.

GARIBA, Y. S. Assessment of Four Plant Extracts as Maize Seed Storage Protectants against Sitophilus Zeamais and Prostephanus Truncatus in Ghana. 2018. Tese de Doutorado. University of Ghana.

HAGSTRUM, D. W.; PHILLIPS, T. W. Evolution of Stored-Product Entomology: Protecting the World Food Supply. Annual Review of Entomology, p. 379-397, 2017.

HIKAL, W. M.; BAESHEN, R. S.; SAID-AL AHL, H. A. H. Botanical insecticide as simple extractives for pest control. Cogent Biology, v. 3, p. 1-16, 2017.

HU, Y. et al. Mechanisms of antifungal and anti-aflatoxigenic properties of essential oil derived from turmeric (Curcuma longa L.) on Aspergillus flavus. Food chemistry, v. 220, p. 1-8, 2017.

JIMENEZ-GARCIA, S. N. et al. Fusarium Mycotoxins and Metabolites that Modulate Their Production. Fusarium - Plant Diseases, Pathogen Diversity, Genetic Diversity, Resistance and Molecular Markers, 2018. DOI: 10.5772/intechopen.72874. Disponível em: https://www.intechopen.com/books/fusarium-plant-diseases-pathogen-diversity-geneticdiversity-resistance-and-molecular-markers/fusarium-mycotoxins-and-metabolites-thatmodulate-their-production. Acesso em: 29 jul. 2020.

JNR, I. Y.; ABUGRI, A. D.; AFUN, J. V. K. Efficacy of ethanolic leaf extract of Chromolaena odurata in controlling Sitophilus zeamais in stored maize. Journal of Experimental Agriculture International, p. 1-10, 2016.

KALAGATUR, N. K. et al. Discrete and combined effects of Ylang-Ylang (Cananga odorata) essential oil and gamma irradiation on growth and mycotoxins production by Fusarium graminearum in maize. Food Control, v. 94, p. 276-283, 2018. 
KAVALLIERATOS, N. G. et al. Effectiveness of eight essential oils against two key storedproduct beetles, Prostephanus truncatus (Horn) and Trogoderma granarium Everts. Food and Chemical Toxicology, v. 139, p. 1-13, 2020.

LIKHAYO, P. et al. Maize grain stored in hermetic bags: Effect of moisture and pest infestation on grain quality. Journal of Food Quality, p. 1-9, 2018.

LIMA, J. C. L. Manejo fitossanitário da cultura do milho (Zea mays L.) utilizando defensivos naturais. 2019. $56 \mathrm{f}$. Trabalho de conclusão (Bacharelado em Engenharia de Biossistemas) - Universidade Federal de Campina Grande, Sumé, 2019.

LORINI, I. Perdas anuais em grãos armazenados chegam a $10 \%$ da produção nacional. Visão agrícola, v. 13, p. 127-129, 2015.

MACHINGURA, J. Assessment of grain protection through the incorporation of Eucalyptus citriodora leaves in grain/insecticide admixtures in Zimbabwe. Journal of Horticulture and Postharvest Research, v. 2, p. 49-60, 2019.

MBATA, G. N.; IVEY, C; SHAPIRO-ILAN, D. The potential for using entomopathogenic nematodes and fungi in the management of the maize weevil, Sitophilus zeamais (Motschulsky) (Coleoptera: Curculionidae). Biological Control, v. 125, p. 39-43, 2018.

MIDEGA, C. A. O. et al. Managing storage pests of maize: Farmers' knowledge, perceptions and practices in western Kenya. Crop Protection, v. 90, p. 142-149, 2016.

MINKS, F. Ação de óleos essenciais na persistência da mortalidade do gorgulho e sobre atributos de qualidade fisiológica de sementes de milho. 2019. $34 \mathrm{f}$. Trabalho de conclusão (Bacharelado em agronomia) - Universidade Federal da Fronteira Sul, Cerro Largo - RS, 2019.

MOHAMED, C. et al. Use of bioactive chitosan and Lippia multiflora essential oil as coatings for maize and sorghum seeds protection. EurAsian Journal of BioSciences, v. 14, n. 1, p. 27 34, 2020.

MORAES, S. P. C. B. Controle com óleos essenciais dos fungos Aspergillus sp. e Sclerotinia sclerotiorum no tratamento de sementes de feijão durante o armazenamento. 2018. $81 \mathrm{f}$. Dissertação (Mestrado em Produção Vegetal) - Universidade Federal do Espírito Santo, Alegre, 2018.

MUCHIRIRI, B. Efficacy of Aloe Marlothii Formulations in Controlling Larger Grain Borer (Prostephanus Truncatus) in Different Maize (Zea Mays) Varieties. 2018. Tese de Doutorado. BUSE.

NASERI, B. et al. Fumigant toxicity and sublethal effects of Artemisia khorassanica and Artemisia sieberi on Sitotroga cerealella (Lepidoptera: Gelechiidae). Journal of Insect Science, v. 15, n. 5, p. 1-7, 2017.

NERILO, S. B. et al. Antifungal activity and inhibition of aflatoxins production by Zingiber officinale Roscoe essential oil against Aspergillus flavus in stored maize grains. Ciência Rural, v. 50, n. 6, 2020. 
NGOM, D. et al. Varietal susceptibility of maize to larger grain borer, Prostephanus truncatus (Horn) (Coleoptera; Bostrichidae), based on grain physicochemical parameters. PLoS ONE, v. 15, n. $4, \quad 2020.40$ Disponível https://journals.plos.org/plosone/article?id=10.1371/journal.pone.0232164. Acesso em: 17 jul. 2020.

NKECHI, E. F. et al. Effects of aqueous and oil leaf extracts of Pterocarpus santalinoides on the maize weevil, Sitophilus zeamais pest of stored maize grains. African Journal of Agricultural Research, v. 13, n. 13, p. 617-626, 2018.

OKEREKE, V.; GODWIN-EGEIN, M.; MORDI, C. In vitro evaluation of leaf extracts on the growth of Aspergillus niger infecting maize grains. Azarian Journal of Agriculture, v. 4, n. 1, p. 12-17, 2017.

OSIPITAN, A. A. et al. Evaluation of bee propolis and some plant products in the management of Larger Grain Borer, Prostephanus truncatus (Coleoptera: Bostrichidae) in stored maize. International Journal of Agriculture and Biosciences, v. 7, n. 3, p. 135-138, 2018.

OUATTARA, S. et al. Antifungal activity of Cochlospermum panchonii hook rhizomes essential oil on eight phytopathogenic fungi. Research Journal of Life Sciences, Bioinformatics, Pharmaceutical and Chemical Sciences, v. 4, n. 4, p. 626-636, 2018.

PERCZAK, A. et al. The Inhibitory Potential of Selected Essential Oils on Fusarium spp. Growth and Mycotoxins Biosynthesis in Maize Seeds. Pathogens, v. 9, n. 1, p. 23, 2020.

PESCHIUTTA, M. L. et al. Effectiveness of Mexican oregano essential oil from the Dominican Republic (Lippia graveolens) against maize pests (Sitophilus zeamais and Fusarium verticillioides). AGRISCIENTIA, v. 33, n. 2, p. 89-97, 2016.

PIMENTEL, M. A. G. et al. Recomendações de boas práticas de armazenamento de milho em espiga para agricultura familiar. Embrapa Milho e Sorgo-Circular Técnica (INFOTECAE), 2011.

RIBEIRO, I. A. T. A. et al. Chemical characterization and insecticidal effect against Sitophilus zeamais (maize weevil) of essential oil from Croton rudolphianus leaves. Crop Protection, v. 129, p. 1-7, 2019.

RIBEIRO, L. P. et al. Searching for promising sources of grain protectors in extracts from Neotropical Annonaceae. Boletín Latinoamericano y del Caribe de Plantas Medicinales y Aromáticas, v. 15, n. 4, p. 215-232, 2016.

RIBEIRO, L. P.; LOVATTO, M.; VENDRAMIM, J. D. Avaliação da eficácia de duas formulações comerciais de terra de diatomácea no controle do gorgulho-do-milho com base em parâmetros toxicológicos. Agropecuária Catarinense, Florianópolis, v. 31, n. 1, p. 56-60, 2018. Disponível em: http://publicacoes.epagri.sc.gov.br/index.php/RAC/article/view/111. Acesso em: 22 jan. 2020.

RIBEIRO, L. P.; VENDRAMIM, J. D. Associação de extratos vegetais e terra de diatomácea no controle do gorgulho-do-milho Sitophilus zeamais MOTS. (Coleoptera: Curculionidae). 
Revista Brasileira de Agropecuária Sustentável, v. 9, n. 1, p. 9-16, 2019. Disponível em: https://periodicos.ufv.br/rbas/article/view/7966. Acesso em: 21 jan. 2020.

SANTOS, J. P. Controle de Pragas Durante o Armazenamento de Milho. Sete Lagoas MG: Embrapa, 2006, 20 p. (Circular técnica, 84).

SCAZZOCCHIO, C. Aspergillus: A Multifaceted Genus. Encyclopedia of Microbiology, p. 262-292, 2019.

SENAR, Serviço Nacional de Aprendizagem Rural. Grãos: armazenamento de milho, soja, feijão e café. Brasília: Senar, 2018. 100 p. (Coleção SENAR 216). Disponível em: https://www.cnabrasil.org.br/assets/arquivos/216-ARMAZENAMNTOS-GR\%C3\%83OS.pdf. Acesso em: 10 jun. 2020.

SILVA, M. I. P. Avaliação do extrato vegetal de moringa no controle de fungos em sementes de milho. 2018. $38 \mathrm{f}$. Trabalho de conclusão (Bacharelado em Engenharia agrícola e ambiental) - Universidade Federal de Mato Grosso, Rondonópolis, 2018.

SM, K. et al. Bioefficacy of Selected Plant Extracts against Sitophilus zeamais on Post-Harvest Management of Zea mays. The Journal of Phytopharmacology, v. 7, n. 4, p. 384-391, 2018. Disponível em: http://www.phytopharmajournal.com/Vol7_Issue4_06.pdf. Acesso em: 03 jun. 2020.

SOUJANYA, P. L. et al. Potentiality of botanical agents for the management of post harvest insects of maize: a review. Journal of Food Science and Technology, v. 53, p. 2169-2184, 2016.

TANKA, V. D. Effect of Temperature On, And the Efficacy of Eucalyptus Leaf Extracts Against Sitophilus Zeamais Motschulsky (Coleoptera: Curculionidae) in Stored Maize. 2018. Tese de Doutorado. University of Ghana.

TOFEL, K. H. et al. Degradation of azadirachtin A on treated maize and cowpea and the persistence of Azadirachta indica seed oil on Callosobruchus maculatus and Sitophilus zeamais. Journal of Stored Products Research, v. 69, p. 207-212, 2016.

TOFEL, K. H. et al. Insecticidal products from Azadirachta indica and Plectranthus glandulosus growing in Cameroon for the protection of stored cowpea and maize against their major insect pests. Industrial Crops \& Products, v. 110, p. 58-64, 2017.

USSEGLIO, V. L. et al. Volatile organic compounds from the interaction between Fusarium verticillioides and maize kernels as a natural repellents of Sitophilus zeamais. Journal of Stored Products Research, v. 73, p. 109-114, 2017.

VERMA, R. K. et al. Studies on the biology and evaluation of different plant-based powders as grain protectant against Sitotroga cerealella (Olivier) on maize grains. Research on Crops, v. 17, n. 4, p. 740-744, 2016.

WENNECK, G. S. et al. Deterrência à alimentação e à oviposição de Sitophilus zeamais Motschulsky (Coleoptera: Curculionidae) pelo uso pós vegetais em milho armazenado. Colloquium Agrariae, v. 16, n. 2, p. 50-59, 2020. Disponível em: https://revistas.unoeste.br/index.php/ca/article/view/3062. Acesso em: 23 jun. 2020. 